\title{
Subjetividades des(re)territorializadas no ensino de filosofia: uma análise das práticas e saberes de professores não graduados em filosofia
}

Daniel Santini Rodrigues ${ }^{1}$

\begin{abstract}
Resumo
O Ensino de Filosofia no Brasil atravessa um período de incertezas diante da lei de Reforma do Ensino Médio, de 2017 e com a sua nova Base Nacional Comum Curricular. Diante disso, deseja-se pensar a contribuição da Filosofia no currículo do Ensino Médio e nos efeitos que essa presença provoca nos sujeitos-professores desta disciplina, de modo especial, os não graduados em Filosofia. Este artigo fundamenta-se nos estudos de Michel Foucault, de Gilles Deleuze e de Félix Guattari, que apresentam conceitos que servirão para analisar a constituição da subjetividade des(re)territorializada a partir das "escritas de si" destes professores. Espera-se despertar a resistência na comunidade acadêmica diante das imposições da macroestrutura, consciente da responsabilidade que a Filosofia traz em si.

Palavras-chave: Ensino de filosofia; Constituição da subjetividade; Desterritorialização; Foucault; Deleuze-Guattari.
\end{abstract}

The de(re)territorialized subjectivities in the teaching of philosophy: an analysis of the practices and knowledge of no-graduate teachers of philosophy

\section{Abstract}

The Brazilian teaching of Philosophy is going through a period of uncertainties due to the new Law of Reform of the High School, with its new Basis for the National Common Curriculum. Based on this, the Professors want to think about the contribution of Philosophy in the curriculum of Brazilian High School, and its effects provoked on the subjected teachers of Philosophy, and, in a particular way, the under-graduates in Philosophy. This research is substantiated in the studies of Michel Foucault, Gilles Deleuze and Félix Guattari, who present concepts that will serve to analyze the constitution of the subjectivity of de(re)territorialized that starts at the "writings of myself" from those professors. This report aims to awake the resistance of the academic community in front of the impositions of the macro-structure, which is aware of the responsibility that Philosophy brings in itself.

Keywords: The teaching of philosophy; The constitution of the subjectivity; Deterritorialization; Foucault; DeleuzeGuattari.

\section{Considerações iniciais: Filosofia, currículo do Ensino Médio e discussões atuais}

A política educacional tem enfatizado crescentemente o oferecimento de uma educação mais técnica em detrimento de uma perspectiva mais humanista, o que tem provocado a redução da carga horária, ou até o fim da obrigatoriedade de disciplinas como Filosofia ou Sociologia.

Embora a disciplina Filosofia tenha retornado ao currículo do Ensino Médio, em 2008,

\footnotetext{
${ }^{1}$ Faculdade Católica de Pouso Alegre, Diretor Geral e Professor dos cursos de graduação em Filosofia e Teologia, bolsista Capes, Cachoeira de Minas, dsantinirodrigues@uol.com.br.
}

Periódico Horizontes - USF - Itatiba, SP - Brasil - e019031 
com a Lei 11.684 (BRASIL, 2008), que tornou obrigatório o seu ensino após anos de luta e de esforço para esta inclusão, correntes utilitaristas e pragmáticas, que atravessam a educação brasileira, fizeram com que a Filosofia começasse a ser vista de outra forma: de uma disciplina, que no passado tinha um destaque e era compreendida como primordial, dentro de uma perspectiva humanística de educação, para a incerteza do seu oferecimento como disciplina ou até mesmo de seu conteúdo de forma interdisciplinar.

Esta incerteza atual é fruto da Reforma do Ensino Médio, através da lei 13.415 (BRASIL, 2017), de 16 de fevereiro de 2017, e da nova Base Nacional Comum Curricular do Ensino Médio (BNCC/EM) (BRASIL, 2018), anunciada pelo Ministério da Educação (MEC), em 3 de abril de 2018, que não explicita como a Filosofia é integrada no currículo. Mas se faz necessário pensar na contribuição da Filosofia no currículo do Ensino Médio e nos efeitos que essa presença provoca nos sujeitos envolvidos na educação, tendo como foco a análise de sujeitos professores, de modo especial os não-graduados em Filosofia, já que se observou um grande número de professores desta disciplina que não têm a formação específica na área.

A Filosofia possibilita inserir professores e alunos no território das dúvidas, dos questionamentos, das problematizações, ou seja, um espaço de aprender a pensar de outro modo muitas das situações da vida e do mundo, como explicita Danelon (2010, p.115):

\begin{abstract}
A Filosofia é tensional, pois nos tira do lugar comum num chamamento para a inquietude, Em outras palavras, a filosofia, por ser diversa e plural, não se encontra no lugar da verdade universal e inquestionável, ou de conceitos que bastam a si mesmo. Ela é tensional porque o texto filosófico nos tira do território da certeza, lançando-nos no desconforto [...]. Dada a pluralidade de filosofias que trata destas questões, o aluno se vê jogado no lugar da inquietação em não ter respostas definitivas, obrigando-o a produzir argumentos, falas e textos como produto de sua reflexão filosófica.
\end{abstract}

Desta forma, percebe-se que o ensino de Filosofia desestabiliza o território das certezas, colocando em questão verdades sempre aceitas.

Diante desta realidade, este trabalho, fruto de tese de doutorado em Educação, quer exaltar a força transformadora da Filosofia e analisar como a Filosofia atravessa os sujeitosprofessores não graduados em Filosofia e possibilita a constituição de suas subjetividades e singularidades. A abertura à diferença faz surgir desterritorializações e, consequentemente, a 
reterritorializações. É um processo que não tem fim e que perpassa a vida de todo aquele que se coloca neste caminho.

A pesquisa de doutorado, que inspirou este artigo, fundamentou-se nos estudos de Michel Foucault, de Gilles Deleuze e de Félix Guattari, que apresentam conceitos que serviram para analisar e problematizar o ensino de Filosofia nas escolas e pensar os modos de constituição da subjetividade e singularidade do professor de Filosofia no Ensino Médio, não graduado em Filosofia, que vivencia um processo de des(re)territorialização, a partir das "escritas de si" destes professores.

Por isso, primeiramente, deseja-se apresentar o conceito de "escrita de si" e sua relação na constituição da subjetividade do sujeito no pensamento foucaultiano. Neste processo de constituição de subjetividade, o sujeito vai se singularizando por meio do processo de desterritorialização e reterritorialização; na seção seguinte, na perspectiva de Deleuze-Guattari. $\mathrm{Na}$ sequência, deseja-se integrar os conceitos abordados para pensar a constituição da subjetividade des(re)territorializada do sujeito-professor, a partir das práticas e saberes de dois professores de Filosofia não graduados na área específica. Por fim, as Considerações Finais abordarão questões em aberto referentes ao Ensino de Filosofia e o grande convite à reflexão da resistência da comunidade escolar diante das normativas impostas pelas instâncias superiores.

\section{Foucault: a "escrita de si" e a constituição de subjetividades}

O objetivo de Foucault é criar uma história dos diferentes modos pelos quais os seres humanos se tornaram sujeitos: estes modos de subjetivação são as práticas de constituição do sujeito. Estas práticas se referem às formas de atividade sobre si mesmo. Ele utiliza os conceitos de "práticas de si", "técnicas de si" e "cuidado de si", extraídos da Antiguidade Ocidental grecoromana, para analisar a forma pela qual o sujeito se constitui. Dentro das práticas de si estão as "escritas de si".

Para César Candiotto (2008, p.91). ao se analisar a obra foucaultiana, percebe-se que "o fio condutor da articulação entre subjetividade e verdade é o cuidado de si". Foucault enfatiza que o conhecimento de si jamais é referência fundamental entre os antigos, sendo sempre

$$
\text { Periódico Horizontes - USF - Itatiba, SP - Brasil - e019031 }
$$


referido ao princípio basilar do cuidado de si. Foucault, ao reler Platão, vem apresentar a Filosofia como arte da existência, arte da vida, ou seja, "o cuidado de si torna-se coextensivo à vida" (FOUCAULT, 2010, p.79). O cuidado de si é uma atividade permanente que deve durar a vida toda e que implica sempre uma escolha do modo de vida, isto é, uma separação entre aqueles que escolheram esse modo de vida e os outros. Além disso, o cuidado de si está ligado ao cuidado do outro.

A filosofia como exercício espiritual (askesis) tem como objetivo formar a alma dos alunos. É um exercício de transformação do modo de pensar e de ser. A "escrita de si" é uma forma de escrever para si e para o outro, no entanto, se diferencia de uma "narrativa confessional", na medida em que não possui o objetivo de uma confissão nem o valor de purificação. Ela é uma das formas de exercitar o treino de si em si mesmo com a finalidade de nada mais que a constituição de si num processo de subjetivação, sendo um exercício que possibilita uma abertura para o outro (FOUCAULT, 2012). Desta forma, já se percebe que a escrita de si, que num primeiro momento desempanhava o papel de companheira para atenuar a solidão, progressivamente vai assumindo uma função de exercício pessoal, exercício do pensamento.

Para Foucault, os modos de subjetivação são fundamentais para a constituição do sujeito moral e esses modos de subjetivação aparecem e se desenvolvem historicamente como práticas de si: "[...] como elemento de treinamento de si, a escrita tem, para utilizar uma expressão que se encontra em Plutarco, uma função etopoiéitica: ela é a operadora da transformação da verdade em êthos" (p.144). Ou seja, a escrita de si é uma prática de si, pois possibilita transformar os discursos reconhecidos como verdadeiros em princípios de ação, atravessando o sujeito e agindo na sua constituição.

Para Foucault (2012, p.144), "essa escrita etopoiéitica parece estar localizada no exterior das duas formas já conhecidas e utilizadas para outros fins: os hupomnêmata e a correspondência".

a) Os hupomnêmata

O conceito dos hupomnêmata gregos, trabalhado por Foucault, diz que:

(...) os hupomnemata, no sentido técnico, podiam ser livros de contabilidade,

Periódico Horizontes - USF - Itatiba, SP - Brasil - e019031 
registros públicos, cadernos pessoais que serviam de lembrete. Sua utilização como livro da vida, guia de conduta, parece ter se tornado comum a todo um público culto. Ali se anotavam citações, fragmentos de obras, exemplos e ações que foram testemunhadas ou cuja a narrativa havia sido lida, reflexões ou pensamentos ouvidos ou que vieram à mente. Eles constituíam uma memória material das coisas lidas, ouvidas ou pensadas; assim, eram oferecidos como um tesouro acumulado para a releitura e meditação posteriores (FOUCAULT, 2012, 144).

Continuando sua reflexão sobre esses hupomnêmata, Foucault (2012) não os considera um simples suporte de memória, que poderiam ser consultados de tempos em tempos, nem tampouco se destinam a substituir as eventuais falhas de memória. "Constituem de preferência um material e um enquadre para exercícios a serem frequentemente executados: ler, reler, meditar, conversar consigo mesmo e com os outros etc." (FOUCAULT, 2012, p.144). Com isso, os hupomnêmata registram cada uma dessas anotações, de modo a não permitir que elas caíssem no esquecimento, mas, com a finalidade de servir para posteriores exercícios de retomada destes registros.

Além disso, os hupomnêmata, por mais pessoais que sejam, não devem ser entendidos como diários ou como narrativas de experiências espirituais; não constituem uma "narrativa de si mesmo". Segundo Foucault (2012, p.145), “o movimento que eles procuram realizar é o inverso daquele: trata-se de não buscar o indizível, nem de revelar o oculto, e nem de dizer o não dito, mas de captar, ao contrário, o já dito; reunir o que se pôde ouvir ou ler, e isso com uma finalidade que nada mais é que a constituição de si”. Portanto, os hupomnêmata contribuiem para a constituição de si, pois a retomada destes registros do passado traz a subjetividade do próprio sujeito que os relê, de maneira que, a escrita e a leitura destes registros ajudam a formar a si próprio.

b) A correspondência

A correspondência, na perspectiva de Foucault (2012, p.149), não é um simples prolongamento do caderno de notas e registros, mas sim "uma maneira de cada um se manifestar a si próprio e aos outros". As escritas de si repousam sobre um solo dialógico. Cada palavra escrita se configura como uma proposta de diálogo. Nessa moldura, cada expressão adquire uma forma de ação e de reflexão. Com a troca de correspondências, os conselhos escritos mutuamente desempenham a função educacional de aproveitar a experiência do outro para si próprio.

Afirma Foucault (2012, p.152): “a carta faz o escritor 'presente' àquele a quem a dirige". 
E é "presente" não apenas nas informações que lhe dá acerca da sua vida, das suas atividades, dos seus sucessos e fracassos, das suas venturas ou infortúnios; presente com uma espécie de presença imediata e quase física. O sentido no dito sobre si não se reduz ao que está posto no significado semântico das palavras escritas, mas se completa, ganha força e vivacidade naquilo que está marcado com a motivação da fala e na possibilidade da escuta. A "escrita de si" está perpassada de intersubjetividade. Portanto, a "escrita de si" na Antiguidade clássica se inseria num quadro de investimentos em práticas de liberdade, práticas intersubjetivas e relacionais com o mundo exterior que visavam à autoelaboração constante. Dessa forma, "tem-se um sujeito voltado para seu exterior, sendo a verdade recolhida e meditada e não revelada por Deus ou a ciência" (IONTA, 2013, p.14).

“Na modernidade, a 'escrita de si' tornou-se confissão, o sujeito está voltado para seu interior, a verdade não é mais recolhida e construída, mas revelada por Deus, como no cristianismo e, depois, através da ciência, nas sociedades dessacralizadas" (IONTA, 2013, p.14). Foucault (2009, p.141) evidencia que "a escrita como exercício pessoal praticado por si e para si é uma arte da verdade contrastiva: ou, mais precisamente, uma maneira refletida de combinar a autoridade tradicional da coisa já dita com a singularidade da verdade que nela se afirma e a particularidade das circunstâncias que determinam o seu uso".

Ou seja, a "escrita de si" permite uma prática de liberdade a fim de inscrever na alma a experiência modificadora de si, na prática de constituição da subjetividade. Portanto, a "a escrita de si" é um exercício de si em vista de se constituir como sujeito.

As entrevistas, realizadas com os sujeitos professores participantes desta pesquisa, foram consideradas como "escritas de si", pois apresentam o falar franco (parrhesía) de cada sujeito participante que faz um exercício de si em si mesmo com a finalidade de analisar discursivamente sua própria constituição da subjetividade.

\section{Deleuze e Guattari: a des(re)territorialização no processo de constituição de subjetividades e} singularidades

O conceito de desterritorialização, criado por Deleuze e Guattari, foi introduzido através da obra O Anti-Édipo (DELEUZE; GUATTARI, 2010a), publicado originalmente em 1972 e, 
posteriormente, desenvolvido sobretudo em Mil Platôs (DELEUZE; GUATTARI, 2011) e em O que é a filosofia? (DELEUZE, GUATTARI, 2010b). Com este conceito, Deleuze e Guattari pensam como se dá a construção e a destruição ou abandono dos territórios humanos, quais são os seus componentes, seus agenciamentos e suas intensidades. Mas, prioritariamente, faz-se necessário esclarecer o que estes autores propõem conceitualmente como sendo os processos de desterritorialização.

Deleuze e Guattari sempre tiveram no conceito de território e nos processos de desterritorialização e reterritorialização importantes ferramentas para o entendimento não apenas das questões filosóficas, mas também das práticas sociais e na construção de um efetivo projeto político de libertação dos desejos, dos corpos, da arte, da criação e da produção de subjetividade. Por isso, para eles a filosofia é uma geofilosofia, que é o título, inclusive, de um dos capítulos da obra O que é a Filosofia?.

Esta perspectiva filosófica de Deleuze e Guattari é inspirada no pensamento de Nietzsche, para o qual não há uma verdade universal sobre os acontecimentos e nem uma moral possível para balizar os fatos históricos:

Para Nietzsche, a verdade não passa de um valor moral que é, sobretudo, estabelecido pelos próprios filósofos. Deste modo, filosofar teria de envolver a criação de valores novos e não apenas confirmar os já criados pela tradição e tidos como verdadeiros. A ironia com que o autor se refere ao filósofo alemão Kant, com relação aos livros de críticas, faz Deleuze e Guattari afirmarem que foi Nietzsche quem fundou a geofilosofia, isto é, esta nova maneira de pensar pelo lado de fora do sujeito e do objeto (MOSTAFA; NOVA CRUZ, 2009, p.81).

Por isso, inspirado em Nietzsche, Deleuze e Guattari convidam a olhar para a Filsoofia com outros olhos, pois a Filosofia clama pelo novo e pelo movimento e, consequentemente, pensar é habitar um terreno e relacionar-se com ele. Por isso, a filosofia é uma gefilosofia, pois está em constante processo de territorializações, desterritorializações e reterritorializações.

Primeiramente, faz-se necessário compreender o conceito de território. Deleuze e Guattari, ao convidarem seus leitores a pensar de outro modo, afirmam que "pensar não é nem um fio estendido entre um sujeito e um objeto, nem um revolução de um em torno do outro. Pensar se faz antes na relação entre o território e a terra" (DELEUZE; GUATTARI, 2010b, p.103). Ou seja, para Deleuze e Guattari não importa se se começa com o objeto, como querem os 
materialistas ou empiristas, ou se se começa com o pensamento, como querem os idealistas ou racionalistas. Desta forma, pode-se afirmar que só se pensa sobre um território, como afirmavam os gregos e como Deleuze e Guattari retomam, mas em movimento infinitos e ininterruptos de tal forma que supere qualquer forma de pensamento sedentário.

Na nova proposta, Deleuze e Guattari propõem pensar com base na relação entre território e terra. "Essa imagem de sujeito e objeto não é adequada porque supõe julgamentos, isto é, que podemos julgar tudo: quem e quais são os sujeitos de fato e de direito, como e quais são os objetos merecedores de nossa atenção" (MOSTAFA; NOVA CRUZ, 2009, p.80). Assim Deleuze e Guattari justificam sua posição:

Kant é menos prisioneiro que se acredita das categorias de objeto e de sujeito, já que sua ideia de revolução copernicana põe diretamente o pensamento em relação a terra; Husserl exige um solo para o pensamento, que seria como a terra, na medida em que não se move nem está em repouso, como intuição originária. Vimos, todavia, que a terra não cessa de operar um movimento de desterritorialização in loco, pelo qual ultrapassa todo território: ela é desterritorializante e desterritorializada (DELEUZE; GUATTARI, 2010b, p.103).

Desta forma, Deleuze e Guattari ao deslocarem o pensamento do sujeito e do objeto, procuram pensar nos movimentos que este encontro promove na terra, que contemplam os constantes processos de territorialização, desterritorialização e reterritorialização. A desterritorialidade é movimento no qual um território é abandonado e a reterritorialização é um movimento de construção de um território.

O conceito de território decerto implica o espaço, mas não consiste na delimitação objetiva de um lugar geográfico. O valor do território é existencial: ele circunscreve, para cada um, o campo do familiar e do vinculante, marca as distâncias em relação a outrem e os protege do caos (ZOURABICHVILI, 2009, p.46).

Percebe-se, então, que na perspectiva do pensamento de Deleuze e Guattari, o território pode ser relativo tanto a um espaço vivido, quanto a um sistema percebido, de subjetivação, ganhando amplitude maior, pois os autores o articulam com o pensamento e o desejo.

Segundo Deleuze e Guattari (2010b, p.103), os corpos estão em movimento assim como a própria terra: "Ela se confunde com o movimento daqueles que deixam em massa seu Periódico Horizontes - USF - Itatiba, SP - Brasil - e019031 
território, lagostas que se põem a andar em fila no fundo da água, peregrinos ou cavaleiros que cavalgam numa linha de fuga celeste" (DELEUZE; GUATTARI, 2010b, p.103). A partir disto, Deleuze e Guattari propõem a filosofia da terra em que a filosofia se confunde com o lugar, de tal forma que os corpos estão em permanentes processos de desterritorialização, toda vez que se movem na terra. Mas mesmo que pareçam estar parados como as rochas e as árvores, os corpos estão sempre em movimento:

\begin{abstract}
A terra não é um elemento entre outros, ela reúne todos os elementos num mesmo abraço, mas se serve de um ou de outro para desterritorializar o território. Os movimentos de desterritorialização não são separáveis dos territórios que se abrem sobre um alhures, e os processos de reterritorialização não são separáveis da terra que restitui territórios. São dois componentes, o território e a terra, com duas zonas de indiscernibilidade, a desterritorialização (do território à terra) e a reterritorialização (da terra ao território). Não se pode dizer qual é primeiro (DELEUZE; GUATTARI, 2010b, p.111).
\end{abstract}

Desta forma, a reterritorialização e a desterritorialização são processos concomitantes, fundamentais para compreender a constituição de subjetividades e singularidades.

Para ilustrar sua criação conceitual, Deleuze e Guattari (2010b, p.103) perguntam-se em que sentido a Grécia é o território do filósofo ou a terra da filosofia e concluem que isto se deve ao encontro da terra com o pensamento. Segundo os filósofos, a Grécia tem uma geografia fractal, em que todos os pontos da península estão perto do mar, o que faz dos gregos os navegadores. As suas cidades formam, assim, um meio de imanência, um meio favorável ao contato, como se fosse um mercado internacional onde os artesãos e os mercadores encontram mais liberdade e mobilidade para seus movimentos. Inclusive os pensadores estrangeiros ao chegarem à Grécia, também se tornam filósofos. Deleuze e Guattari explicam o que os emigrados encontram no meio grego:

Três coisas ao menos, que são as condições de fato da filosofia: uma pura sociabilidade como meio de imanência, "natureza intrínseca da associação" [...]; um certo prazer de se associar, que constitui a amizade, mas também de romper a associação, que constitui a rivalidade; um gosto pela opinião, inconcebível num império, um gosto pela troca de opiniões, pela conversação (DELEUZE; GUATTARI, 2010b, p.106). 
Com isto, Deleuze e Guattari explicam porque a Grécia foi o território da filosofia e reforçam a relação entre território e pensamento.

Portanto, percebe-se que Deleuze e Guattari estão preocupados com o acontecimento, sua história e seu devir e desejam mostrar os acontecimentos nos seus encontros, suas dobras e redobras. A partir deste processo de desterritorialização, o ser está em constante ressignificação e num constante movimento, possibilitando se constituir como sujeito, singularizando-se como ser da diferença.

\section{O Ensino de Filosofia e a singularidade do sujeito-professor não graduado em Filosofia:}

\section{subjetividade des(re)territorializada}

A coleta de dados da pesquisa de doutorado, que originou este artigo, foi efetuada através de 8 (oito) entrevistas com professores de Filosofia do Ensino Médio, sendo metade de graduados em Filosofia e a outra metade de não graduados em Filosofia, em escolas da região do Sul de Minas Gerais². Este artigo se restringe à análise do processo de des(re)territorialização de apenas dois professores não graduados em Filosofia por assumirem esta disciplina, ambos na rede pública estadual. Ou seja, deseja-se analisar os efeitos do ensino de Filosofia na constituição da subjetividade-singularidade de apenas dois sujeitos-professores denominados "Sujeito $\mathrm{A}^{\text {" }} \mathrm{e}$ "Sujeito B"4.

Em consonância com a perspectiva discursiva, que tem como proposta apresentar não o "sujeito falante", mas o "sujeito falando" em sua real condição sócio-histórico-ideológica, esta pesquisa serviu das convenções de transcrição propostas por Marcuschi (2004) a fim de manter, o máximo possível, a fidelidade ao texto falado, destacando, na transcrição, ênfases, pausas menores e maiores, repetições, redundância informacional, hesitações, entre outros. Além disso, a formatação de todos os excertos das entrevistas segue as normas de citação direta acima de três linhas, e diferencia-se na formatação em itálico em sua íntegra.

\footnotetext{
2 O referido projeto de pesquisa foi aprovado no Comitê de Ética e Pesquisa da Universidade São Francisco, com o número CAAE 46103215.6.0000.5514 e segue os preceitos estabelecidos, diretrizes e normas por envolver seres humanos em pesquisas, de acordo com a Resolução 466/12 de 12/12/2012 do Conselho Nacional da Saúde, que atualiza as Resoluções 196/96, 303/2000 e 404/2008.

${ }^{3} \mathrm{O}$ "Sujeito A" refere-se ao "Sujeito Participante 2" da pesquisa de doutorado.

${ }^{4} \mathrm{O}$ "Sujeito B" refere-se ao "Sujeito Participante 6" da pesquisa de doutorado.
}

Periódico Horizontes - USF - Itatiba, SP - Brasil - e019031 
Através das escritas de si dos sujeitos-professores envolvidos na pesquisa percebeu-se o quanto a filosofia desperta processos de des(re)territorialização, pois os professores deixaram ser afetados pela Filosofia e iniciaram processo de transformações em seu modo de pensar e de agir, estando em constante devir.

a) A Constituição da subjetividade e da singularidade do Sujeito A e seu processo de des(re)territorialização.

O Sujeito A é uma professora de 36 anos, com 5 anos de experiência docente. Somente no ano de 2015 iniciou a docência de Filosofia no Ensino Médio em uma instituição pública estadual, ou seja, está apenas no seu primeiro ano de experiência. Ela não tem graduação em Filosofia e, atualmente, cursa a faculdade de Matemática. Ela não tem o hábito de ler nenhuma obra filosófica e suas leituras para a preparação de aula são os livros que a própria escola fornece. Além disso, ela analisa que seu conhecimento filosófico é superficial, e também narra que lê um livro que fala da vida dos filósofos, mas sem procurar ler os próprios filósofos. Este sujeito participante da pesquisa não apresentou nenhum filósofo ou corrente filosófica que embase sua vida.

Mas o sujeito A, mesmo sem ter sua graduação em Filosofia e nem ter um envolvimento com os estudos filosóficos anteriormente à docência desta disciplina, tem sido afetado nos seus poucos meses como professora de Filosofia no Ensino Médio. Precisou desterritorializar-se e reterritorializar-se.

Ela assumiu a disciplina pelo fato de a função estar vacante e por necessidade, como a própria escreve: "veio a oportunidade de eu assumir o cargo de Filosofia... primeiramente por falta de professor e segundo por NECESSIDADE".

Ou seja, os enunciados "por falta de professor" e "por necessidade" carregam as motivações iniciais que possibilitaram à professora assumir a docência de Filosofia. E a mesma nem imaginava a transformação que estaria a ocorrer na sua vida com esta escolha.

Interessante é sua análise sobre o efeito da disciplina de Filosofia não só na professora, mas também nos alunos. Percebe-se uma abertura do sujeito participante para que a Filosofia possa provocar mudanças em si e nos que estão ao seu redor: 
Filosofia eu acho que não causa SÓ no professor... causa TAMBÉM nos alunos... é uma JUNÇÃO na sala de aula professor e aluno... nos debates nas CONVERSAS filosóficas... SEMPRE ali alguém acha um PONTO de parecer com sua vida ou então que vai mudar a sua vida daqui para frente.

Neste excerto, a professora 2 cita duas vezes o enunciado "causar", manifestando uma compreensão inicial da Filosofia como algo que provoca, que afeta, que transforma. Em sua narrativa, relata que esta empreitada do exercício filosófico é realizada de forma conjunta, professor e aluno, não apresentando com clareza a concepção da Filosofia como modo de vida, mas dá indícios de que a Filosofia provoca efeitos na vida tanto do professor quanto do aluno, como explicitados nos enunciados "acha um ponto de parecer com sua vida" e "vai mudar a sua vida".

O destaque neste excerto é a importância dada para o diálogo no exercício do filosofar, através da metodologia de aula baseada em debates e conversas filosóficas. Um retorno para a prática socrática faz-se necessário, pois mesmo sem a professora ter um conhecimento aprofundado sobre o método dialético, ela o pratica em sala de aula junto aos seus alunos.

Diante dos desafios, o sujeito participante pensou em desistir, mas foi motivada a continuar, inclusive pelos alunos:

eu tive ao ponto de querer desistir das aulas de verdade porque assim... OS ALUNOS eles estão além dos limites... eles sabem ...eles querem explorar MESMO e eu vi que eu estava com um pouco de dificuldade para atender a demanda deles para comigo como professora de Filosofia... e eu cheguei a um ponto de chegar ao diretor da escola e falar... olha não consigo VOU desistir... mas aí com o apoio DEle:: do meu esposo... não... vamos tentar NOVAvamente vamos mudar... vamos VER aí com a ajuda DOS ALUNOS.

Através deste último excerto, dois elementos merecem destaque na constituição da subjetividade da professora A. Primeiro, a professora se coloca frente ao saber numa atitude de humildade, diante do interesse e conhecimento dos próprios alunos, e ela se abre ao diferente e aceita o desafio de se deixar ser transformada pela Filosofia. Segundo, o fato dos alunos provocarem a permanência do sujeito A como docente. A professora aceita continuar como professora assumindo a disposição de mudança, como narra o enunciado: "vamos tentar novamente... vamos mudar". Na repetição, emerge a diferença. Na resistência, surge a linha de 
fuga, a dobra, que possibilita uma singularidade.

E a professora A, na sua "escrita de si", relata que a maneira dos alunos praticarem a Filosofia tem afetado a sua vida e provocado mudanças:

eu assumindo as aulas ESTRANHEI MUITO... estranhei muito porque eu achei que eles queriam mais... uma coisa mais centrada e não... eles gostam muito de DEBATER a vida do dos filósofos... eles gostam da Filosofia... a PRÁTICA não só teoria... eles gostam da prática então eles querem encenar (...) e isso eu tive muita dificuldade em APRENDER com eles... até que eu consegui me CENTRAR no que eles queriam.. não é a teoria... chegar passar a matéria explicar e atividade... NÃO... eles querem movimentação... eles querem SER o filósofo... eles querem praticar aquilo que os filósofos praticaram na idade deles.

Neste excerto, a professora A narra seu processo de constituição de subjetividade como professora que conta com alguns elementos. A sua primeira atitude diante das aulas de Filosofia é de estranhamento, pois ela tinha uma expectativa e os alunos outra. A professora se sente amedrontada ao ter que lecionar teorias filosóficas, mas se transforma com a disposição dos alunos em debater e praticar a filosofia. A professora novamente precisa se desterritorializar e ressignificar sua prática docente. A sua "escrita de si", transcrita no excerto acima, apresenta vários enunciados que provocaram mudanças em seu modo de dar aula, a partir das atitudes dos alunos: "eles gostam da prática"; "eles querem encenar", "eles querem movimentação", "eles querem ser o filósofo", que explicitam uma concepção da filosofia como prática, como exercício e que transformam a vida da professora. A professora 2 se põe em movimento. Ela se põe em questão. Ela não teve formação para aprofundar conceitualmente os filósofos e nem era isso que os alunos queriam, mas ela pode, junto com os alunos, encontrar as linhas de fuga da resistência.

E com o exercício da docência de Filosofia, a professora A tem vivenciado a força transformadora da Filosofia, que tem ajudado alunos a verem a vida de um outro modo:

eu venho dando a minha CONTRIBUIÇÃO para aqueles alunos que às vezes estão lá deprimidos com algum motivo (...) eles conseguem enxergar a vida de uma maneira diferente... uma OUTRA vida... uma vida que eles PODEM se transformar... eles podem mudar de vida com a o estudo DA Filosofia... eles podem pensar refletir.

Ao se singularizar, a professora A tem provocado, também, nos alunos um processo de

Periódico Horizontes - USF - Itatiba, SP - Brasil - e019031 
transformação e mudança. No excerto acima, alguns enunciados merecem destaque: "eles conseguem enxergar a vida de uma maneira diferente", "eles podem se transformar", "eles podem mudar de vida". Ao deixar que a Filosofia a afetasse, a professora provoca nos alunos um constante movimento. O seu processo de constituição de subjetividade tem despertado a constituição de outras subjetividades.

Interessante já é a percepção da referida professora do conceito de Filosofia, pois já consegue fazer uma relação entre Filosofia e vida, como narra no excerto a seguir: "Um estudo de mim mesma... um estudo de você mesma, da minha mente mesma do meu AGIR do meu pensar do meu refletir (...) e falar em Filosofia é refletir a VIDA refletir o meu sentimento a minha vida".

Ou seja, a professora, ao se singularizar, fez a experiência concreta da Filosofia em sua vida, compreendendo esta relação intrínseca da Filosofia com a vida.

Portanto, este sujeito A tem uma profunda experiência de transformação no seu jeito de pensar e de conceber a Filosofia e, a partir das resistências encontradas, soube buscar as linhas de fuga para mudar seu modo de ensinar Filosofia: buscou o diálogo com os alunos e acolheu as sugestões. Com este seu processo de constituição de subjetividade, o sujeito participante esteve aberto ao diferente e iniciou um movimento de singularidade de tal forma que encontrou na Filosofia uma forma de olhar o mundo e a escola de outra forma, e de pensar de outro modo.

b) A Constituição da Subjetividade e da Singularidade do Sujeito B e seu processo de des(re)territorialização

O Sujeito B é um professor de 40 anos, sendo 5 anos na docência de Filosofia no Ensino Médio em escola pública. Não tem formação específica em Filosofia, mas tem uma ampla trajetória acadêmica. É graduado em Ciências Sociais pela Universidade Estadual Paulista, de Araraquara. Tem dois mestrados, sendo um em Economia, pela Unicamp e, outro, em Ciência Política Comparada entre Brasil e França, na Sorbonne, na França. Atualmente, está no doutorado em Ciência Política, na Universidade São Paulo. O professor lê muitas obras filosóficas, tendo uma biblioteca pessoal com aproximadamente 3 mil exemplares. Ultimamente ele tem se dedicado à leitura de obras de Nietzsche e manifesta sua predileção também à filósofos da Antiguidade Clássica, a partir de Sócrates, Platão e Aristóteles.

Periódico Horizontes - USF - Itatiba, SP - Brasil - e019031 
Este sujeito participante, apesar de não ter formação específica em Filosofia, tem leituras filosóficas e ampla formação acadêmica. Após estar inserido em grandes universidades do Brasil e do exterior, o referido professor decide migrar para uma pequena cidade do sul de Minas, fazendo a descoberta que a Filosofia atravessava sua vida: "foi só vindo pra cá que eu comecei a descobrir que eu VIVIA no meu dia a dia... MESMO sem saber... filosoficamente ou seja eu (...) gosto de MUDANÇA... eu gosto de ENTENDER a verdade das coisas... eu gosto de saber como elas funcionam".

O professor B, no excerto acima, através do enunciado "eu gosto de mudança", inscreve na escola um modo de vida marcado pelo constante devir e desejo de transformação e deslocamentos. Percebe-se que este sujeito participante da pesquisa tem uma perspectiva foucaultiana de analisar e ver as coisas, pois o mesmo tem interesse em saber o funcionamento das coisas e não as coisas em si, além de gostar de mudanças, ou seja, estava aberto a constantes devires. O professor afirma: "eu gosto de entender como elas funcionam". Desta forma, ele instaura novas práticas dentro da sala de aula, buscando provocar nos alunos diferenças e multiplicidades.

O sujeito B, em sua "escrita de si", revela que inicialmente assumiu a disciplina de Filosofia no Ensino Médio para complementar sua renda, mas depois pôde encontrar na Filosofia as condições para o aprofundamento e a aprendizagem:

Pode parecer estranho mas num local tão SIMPLES simplório que é o Ensino Médio comparado com a ARROGÂNCIA da Universidade (...) COMO eu fui me completando... como eu fui me conhecendo AQUI então no primeiro momento era Só pra complementação de renda depois eu fui percebendo que eu... o meu aprendizado aqui MAIS do que DOBROU... eu fui percebendo algumas coisas que eu FAZIA (...) e fui me descobrindo... tendo mais o ÍMPETO FILOSÓFICO do que eu achava que eu tinha.

Este professor tem grande experiência em sua vida acadêmica e sua subjetividade tem sido constituída neste confronto de inserção em grandes universidades do Brasil e do exterior, principalmente na França, e em sua presença mais recentemente numa escola pública de uma cidade do sul de Minas Gerais. Realidades distintas que têm provocado transformações em sua vida. Comparando-se a arrogância das universidades com a simplicidade das escolas de Ensino Médio, o professor faz uma constatação: "o meu aprendizado aqui mais do que dobrou". Mesmo 
frequentando grandes universidades, o professor faz a experiência de uma aprendizagem mais intensa na efetivação de sua presença numa sala de aula no Ensino Médio, em escola pública. E este processo possibilita ao professor descobertas: "fui me descobrindo... tendo mais o ímpeto filosófico do que eu achava que eu tinha". Ao exercer a filosofia em sala de aula, o professor se vê trilhando um novo caminho de mudança. Este ímpeto filosófico tem provocado mudanças no jeito de pensar e de agir do professor, principalmente no seu relacionamento consigo mesmo:

Eu consigo viver MUITO MAIS em paz comigo mesmo apesar de... como diz todo mundo que me conhece... que eu sou MUITO barulhento... eu penso muito... fico discutindo muito... questionando muito mas eu CONSIGO de mim para comigo mesmo digamos assim eu consigo me sentir MELHOR.

Com base no excerto acima, a filosofia desperta no professor B uma atenção ao cuidado de si, nessa relação de si para si mesmo. Foucault destaca a importância do cuidado de si como condição para o cuidado do outro. Desta forma, percebe-se que o sujeito B tem uma relação consigo mesmo mais satisfatória após seu encontro com a Filosofia. Foram várias as mudanças provocadas em suas práticas: "eu consigo viver muito mais em paz comigo mesmo", "eu penso muito", "discutindo muito", "questionando muito". Estas práticas de si têm provocado deslocamentos no sujeito $B$.

O professor relata que tem dificuldade de despertar nos alunos o interesse pela Filosofia e busca superar isso com a discussão filosófica a partir da vida: "a minha MAIOR dificuldade é fazer com que eles GOSTEM... que eles sintam que HÁ NECESSIDADE da Filosofia e para isso eu tento relacionar a Filosofia com o dia a dia deles. (...) eu acho que PARA algumas pessoas eu consigo alcançar mas para outras AINDA NÃO".

O excerto acima relata a prática filosófica do professor B a partir do cotidiano. Através do pensar e problematizar o dia a dia dos alunos, o professor tem conseguido despertar o interesse dos alunos na filosofia. O professor, ao constituir sua subjetividade, enfrenta a dificuldade e alcança parte de seus objetivos, despertando gosto de alguns alunos pela Filosofia. Mas o professor não perde a esperança de ainda provocar nos demais alunos o mesmo interesse. 0 professor constata: "eu acho que pra algumas pessoas eu consigo alcançar mas para outras ainda não". Sua fala, destacando o termo "ainda" reforça a ideia de que o professor tem 
esperança de contagiar a todos seus alunos com o exercício do filosofar.

Com aqueles que consegue despertar o interesse nas aulas, o professor percebe o amadurecimento do senso crítico, desenvolvendo um olhar de questionamento diante das coisas do mundo: eu me importo MUITO com os meus alunos... com a molecada que está comigo porque eu vejo na Filosofia a construção do senso crítico GIGANTESCO, você não engole qualquer coisa depois disso.

Neste excerto merece destaque alguns enunciados: primeiramente, o professor afirma que se importa muito com os alunos que estão sob seus cuidados na aula de Filosofia. Ter esta cumplicidade é fundamental para despertar no outro o desejo de pensar. Em segundo lugar, os efeitos da Filosofia na vida daqueles que se permitem trilhar o seu caminho. Segundo o professor: "eu vejo na Filosofia a construção do senso crítico gigantesco, você não engole qualquer coisa depois disso". Com esta narrativa de si, o sujeito 6 evoca o caráter transformador da filosofia, provocando senso crítico e posicionamento diferente diante das questões da vida, pois permite pensar e ver a vida de outro modo.

O sujeito 6 percebe que tem muito ainda a se deslocar em sua prática docente, demonstra que gosta da Filosofia, mesmo sem ser filósofo; mas reconhece que tem muito que aprender, principalmente com a forma de pensar do outro, que pode ser diferente da sua:

eu poderia melhorar MUITO... eu precisaria:: não querendo fazer uma meaculpa mas a escola precisava... eu precisava ter... eu acho que eu fico MUITO AQUÉM daquilo que eu posso fazer... não sou filósofo... sou sociólogo... SEMPRE gostei de Filosofia como eu já disse anteriormente... sinto que eu VIVO filosoficamente sem ser um filósofo (...) eu não sou um bom professor... ainda eu tenho muito que aprender no sentido e eu não estou sendo demagogo não... eu tenho mesmo no sentido de CONSEGUIR TRABALHAR a Filosofia... a minha forma de pensar e a forma de pensar DO OUTRO.

Com esta sua "escrita de si", o professor se considera em processo de constituição, pois percebe que poderia melhorar muito. O professor afirma: "eu fico muito aquém daquilo que eu posso fazer". Mesmo não sendo formado em filosofia, mas em sociologia, o professor 6 faz uma experiência de si diante da filosofia: "eu vivo filosoficamente sem ser filósofo". Tudo indica que a referência ao fato de não ser filósofo evoca a sua situação de não ser graduado em Filosofia numa instituição de ensino superior. É sua vida filosófica que tem produzido efeitos de 
transformação em si mesmo, e possibilitado reconhecer sua diferença em relação aos outros, cada um no seu processo de singularidade. Por isso, sente que tem que trabalhar a Filosofia, confrontando a sua forma de pensar e a forma de pensar do outro. O mesmo não se reconhece como bom professor: "eu não sou um bom professor... ainda tenho muito que aprender". Com esta sua experiência, o professor vai constituindo sua subjetividade, pois o desinstala a buscar novas práticas, estando num devir.

Portanto, o sujeito participante B, apesar de não ter formação superior em Filosofia, manifesta ter uma vida atravessada pelo discurso filosófico que o instiga a querer e provocar mudanças em si, nos alunos e na escola. Embora relate sentimentos negativos em relação à sua satisfação como professor de Filosofia na escola, o professor se vê numa tensão entre a acomodação e desvalorização do docente de Filosofia, de um lado; e, de outro lado, as provocações dos filósofos que lê e do retorno de algumas atitudes que seus alunos têm de criticidade dentro da escola, provocando posicionamentos diante de algumas questões pertinentes na escola. Nesta tensão, o professor está constituindo sua subjetividade, pois ele fez um percurso contrário, saindo da academia e de seus estudos de doutorado para adentrar uma sala de aula no Ensino Médio no interior de Minas Gerais. Isso exige deste professor um deslocamento que o possibilite ressignificar sua nova experiência, singularizando sua existência. Muitas foram as experiências de des(re)territorialização em sua vida.

Portanto, percebe-se, ao analisar discursivamente as "escritas de si" dos professores de Filosofia do Ensino Médio, não-graduados em Filosofia, que os dois docentes singularizam suas práticas e passam por processos de desterritorialização e reterritorialização, recriando outros planos de imanências, que os possibilitam estar em constante devir e, com isso, constituindo a subjetividade de cada um como sujeito-professor de Filosofia e exemplificando os efeitos do estudo da Filosofia naqueles que se colocam no caminho do filosofar.

\section{Considerações finais: o ensino de Filosofia no Brasil, perspectivas e desafios}

A partir desta pesquisa, algumas considerações merecem ser ressaltadas para se continuar (re)pensando sobre os efeitos do Ensino de Filosofia no currículo do Ensino Médio:

a) A Filosofia é provocativa, pois desinstala tanto os professores, independentemente de 
sua formação superior, quanto os alunos da zona de conforto e os lança em um território movediço, em que se abrem novos horizontes para a constituição de si e espaços para os movimentos e devires do percurso, os quais quebram a linearidade do traçado, e potencializam a criação do novo e do diferente, singularizando a existência de cada um, pois as singularidades acontecem nos movimentos, nos fluxos, nas linhas de fuga, nas des(re)territorializações.

b) O Ensino de Filosofia é desafiador, pois requer não só conteúdo filosófico ou um saber adquirido, mas também práticas de filosofar, pois se aprende Filosofia fazendo Filosofia. Percebe-se isso, pois mesmo os professores não formados em Filosofia conseguiram, através de uma multiplicidade de escolhas de materiais e exercícios, despertar, primeiramente para si, uma maneira de olhar de outro modo a sua significativa contribuição.

c) A disciplina de Filosofia no currículo do Ensino Médio é des(re)territorializada, pois está sempre em busca de um território, mesmo sabendo que estará sempre em devir, pois esta é a sua natureza. Os movimentos de inclusão ou exclusão, e os períodos de uma presença facultativa, principalmente através de temas transversais, marcaram o desenrolar da história da educação brasileira. Como nômade, a disciplina de Filosofia quer ter uma efetiva participação na educação escolar, através de sua valorização no currículo. Podem até excluí-la do currículo do Ensino Médio, por interesse das políticas públicas, mas a atitude filosófica sempre estará presente através daqueles que se colocaram a caminho do filosofar.

Todo este movimento que a Filosofia provocou na escola faz pensar no direito à filosofia para todos e para todas, como uma política do pensamento, que respeite a autonomia irredutível da filosofia diante das ciências e das religiões:

Tendo-se em conta o que liga a ciência à técnica, à economia, aos interesses político-econômicos ou político-militares, a autonomia da filosofia em face da ciência é tão essencial à prática de um direito à filosofia quanto a autonomia em face das religiões é essencial para quem queira que o acesso à filosofia não seja interdito a nenhuma pessoa, homem ou mulher. Eu faço aqui alusão ao que em cada área cultural, linguística, nacional religiosa, possa limitar o direito à filosofia por razões sociais, políticas ou religiosas, devido à pertença a uma classe, a uma idade, a um sexo - ou a tudo isso ao mesmo tempo (DERRIDA, 2004, p.25).

Como caminho para não se ceder às determinações da macroestrutura, alternativas

Periódico Horizontes - USF - Itatiba, SP - Brasil - e019031 
precisam ser buscadas, como linhas de fuga do sistema, como propõem Juvenal Savian Filho, Marcelo Carvalho e Vinicius Berlendis Figueiredo (2019), membros da Associação Nacional de Pós-graduação em Filosofia (Anpof):

\begin{abstract}
A permanência de filosofia como unidade curricular dependerá da resistência das escolas. Na elaboração de seus projetos pedagógicos, em função da reorganização que virá (definindo especializações na formação), as escolas podem manter o ensino de filosofia. Não apenas as escolas que se especializarão em 'ciências humanas', mas mesmo as escolas especializadas em 'ciências exatas' poderão ter horas de formação em filosofia. A melhor estratégia de resistência, neste momento, parece-nos estar na ação dos professores: começando por seus estudantes e pelo Conselho de Escola, eles podem iniciar um movimento de conscientização: (i) sobre a continuidade da filosofia como unidade curricular; e (ii) sobre a importância da filosofia na formação humana. A partir daí, em união com os professores da escola, do município, do estado e do país, os professores podem e devem lutar para que os projetos pedagógicos das escolas conservem filosofia (como também sociologia, história e geografia!). O MEC e as secretarias estaduais de educação apostarão na atual propaganda derrotista e na possibilidade de as próprias escolas assimilarem a falsa ideia de que a 'filosofia caiu', tirando-a do seu currículo. Se as próprias escolas excluírem por si mesmas a filosofia do Ensino Médio, a 'legitimidade' da retirada será maior (nisso parece investir a BNCC).
\end{abstract}

Portanto, a busca de território está apenas começando. O sonho parece distante, mas é possível, pois a vontade de potência move a Filosofia. Mas a comunidade escolar precisará assumir a resistência diante das imposições, pois está consciente da responsabilidade que a Filosofia traz em si de possibilitar uma experiência modificadora de si, uma experiência do pensar a própria história para saber como podemos ser de outra forma, como pensar de outro modo.

\title{
Referências
}

BRASIL. Presidência da República. Lei n. 11.684, de 2 de junho de 2008. Altera o art. 36 da Lei n: 9.394, de 20 de dezembro de 1996, que estabelece as diretrizes e bases da educação nacional... Disponível em: http://www.planalto.gov.br/ccivil_03/_Ato2007-2010/2008/Lei/L11684.htm. Acesso em: 16 jan. 2019.

BRASIL. Presidência da República. Lei 13.415, de 16 de fevereiro de 2017. Altera as Leis n. 9.394, de 20 de dezembro de 1996, que estabelece as diretrizes e bases da educação nacional, e 11.494, de 20 de junho 2007, que regulamenta o Fundo de Manutenção e Desenvolvimento... Disponível em: http://www.planalto.gov.br/ccivil_03/_ato2015-2018/2017/lei/l13415.htm. Acesso em: 13 abr. 2019.

$$
\text { Periódico Horizontes - USF - Itatiba, SP - Brasil - e019031 }
$$


BRASIL. Ministério da Educação. Base Nacional Comum Curricular, 2018. Disponível em: http://basenacionalcomum.mec.gov.br/images/BNCC_EI_EF_110518_versaofinal_site.pdf. Acesso em: 12 abr. 2019.

CANDIOTTO, C. Subjetividade e verdade no último Foucault. Trans/Form/Ação, São Paulo, n.31, p. 87-103, 2008.

DANELON, M. Ensino de Filosofia e Currículo. Cadernos de História da Educação. v.9, n.1, p.109129, jan/jul.2010.

DELEUZE, G.; GUATARRI, F. O Anti-Édipo. Trad. Luiz B. L. Orlandi. 1.ed. São Paulo: editora 34, 2010a.

DELEUZE, G.; GUATARRI, F. O que é filosofia?. Trad. Bento P. Júnior e Alberto A. Muñoz. São Paulo: editoria 34, 2010b.

DELEUZE, G.; GUATARRI, F. Mil platôs. Trad. Ana Lúcia de Oliveira, Aurélio G. Neto e Célia P. Costa. 2.ed. São Paulo: editora 34, 2011.

DERRIDA, J. O direito à filosofia do ponto de vista cosmopolítico. In: GUINSBURG, J. (Org.). A paz perpétua: um projeto para hoje. São Paulo: Perspectiva, 2004, p.11-29.

FOUCAULT, M. História da Sexualidade 3: o cuidado de si. Trad. Maria T. C. Albuquerque. Rio de Janeiro: Graal, 2009.

FOUCAULT, M. A hermenêutica do sujeito. Trad. Márcio A. Fonseca e Salma T. Muchail. 3. ed. São Paulo: Martins Fontes, 2010.

FOUCAULT, M. Ditos e escritos V: ética, sexualidade, política. In: MOTTA, M. B. (Org.). A escrita de si. Trad. Elisa Monteiro e Inês A. D. Barbosa. 3. ed. Rio de Janeiro: Forense Universitária, 2012, p.143-162.

IONTA, M. Escritas de si em cartas e blogs: figurações da subjetividade feminina. In: RAGO, M.; MURGEL, A. C. A. T. (Orgs.). Paisagens e tramas: o gênero entre a história e a arte. São Paulo: Intermeios, 2013, p.11-24.

MARCUSCHI, L. A. Da fala para a escrita: atividades de retextualização. 5. ed. São Paulo: Cortez, 2004.

MOSTAFA, S. P.; NOVA CRUZ, D. V. Para ler a filosofia de Gilles Deleuze e Féliz Guatarri. Campinas: Alínea, 2009.

SAVIAN FILHO, J.; CARVALHO, M.; FIGUEIREDO, V. B. A BNCC e o futuro da filosofia no ensino médio - hipóteses. Portal da Anpof. Disponível em:

http://www.anpof.org/portal/index.php/en/artigos-em-destaque/1584-a-bncc-e-o-futuro-da-

Periódico Horizontes - USF - Itatiba, SP - Brasil - e019031 
filosofia-no-ensino-medio-hipoteses. Acesso em: 04 mar. 2019.

ZOURABICHVILI, F. O vocabulário de Deleuze. Trad. André Telles. Rio de Janeiro: Relume Durará/Sinergia/Ediouro, 2009.

Recebido em fevereiro de 2019.

Aprovado em abril de 2019. 